\title{
The research of remote earthquakes impact on the intensity of geomechanical processes in burst-hazardous rock massif
}

\author{
Vladimir Lugovoi ${ }^{1 *}$, Igor Rasskazov ${ }^{1}$, Denis Tsoi $^{1}$, Maksim Rasskazov ${ }^{1}$ and Aleksandr \\ Sidliar $^{1}$ \\ ${ }^{1}$ Mining Institute of Far Easten Branch of Russian Academy of Sciences, Khabarovsk, Russia
}

\begin{abstract}
Brief summary of works on the detection of pendulum waves intensifying geomechanical processes in rock massif, with the application of high-sensitivity laser measurements, is represented in the article. Peculiarities and technical characteristics of laser deformograph applied as part of comprehensive geodynamic monitoring system in the area of "Streltsovskoe" ore field have been taken into consideration. The results of experimental research for the evaluation of remote earthquakes impact on the condition of rock massif of "Streltsovskoe" ore field, registration of remote earthquakes and their forerunners are given. Key words: Deformation field, stress-related waves, comprehensive geodynamic monitoring, high-precision laser measurements, rock-burst hazard
\end{abstract}

\section{Introduction}

The occurrence geodynamic activation in large-scale and intense man-made activity which extraction and moving of large volumes of rocks relate to, during solid mineral deposits mining, may be represented by rock-bursts, induced (also in case of impoundment) and other dynamic events, the forecast of which is represented by an actual and simultaneously rather complex problem [1-4]. Reliable forecast of such seismic events and related to them catastrophic phenomena is quite hindered.

The invention, in the end of the previous century, of an event of alternating reaction of rocks to explosion (dynamical) loads gave a great impulse to experimental and theoretical research for the development of fundamentals of pendulum stress-related waves theory [5].

Within the frame of blocks hierarchy model along with fast seismic waves being generated as a result of hard rock destruction, there are slow stress-related waves accompanying the process of elastic energy spread by means of interaction of separate blocks possessing own oscillatory degrees of freedom. Positive results in the registration and record of such waves impact would allow developing new methods for hazardous geodynamic events forecast.

Works on the detection of pendulum waves were being carried out by scientists and specialists from the Institute of Mining of SD RAS and the Institute of laser physics of SD

\footnotetext{
*Corresponding author: lugovoy@dst.khv.ru
} 
RAS over the period from 2006 to 2011 with the use of high-sensitivity laser measurements applied the Institute of laser physics of SD RAS in order for the study of earthquakes forerunners.

During the research, it was made possible to obtain first results on registration of slow pendulum waves accompanying local earthquakes in Baikal Rift Zone. The processing of data on series of earthquakes allowed not only recording them, but also distinguish features and obtaining quantitative evaluation of such waves spread velocity.

In order to record pendulum waves using laser deformographic method, a row of criteria was developed [6].

Main results of deformographic observations comes down to the following [7]:

- the confirmation of existence of the deformation shaking excitation with oscillatory periods within the band of $0.5-2$ hours over 1.5-2 days prior to seismic events obtained;

- the appearance of disturbances in tidal oscillations of the Earth surface over 2-3 days prior to earthquake of class 14 with the focus zone $\sim 530 \mathrm{~km}$ away from observation station recorded;

- the origin of quasi-resonant structure of deformation diagrams - with increasing amplitudes of fundamental harmonic as well as noise term commensurable to the amplitude of tidal wave immediately prior to earthquake was observed;

- correlation relationship between diagrams of Earth crustal deformation change and atmospheric pressure takes place;

- within the frames of hypothesis of condition of earthquake aftershock activity by wave pattern if pendulum waves movement, the evaluation of $\mu$-waves spread velocities with the use of laser deformographic and seismological records is performed. For earthquakes of energy classes of $K=14.1 \div 14.6$, the velocity range of these waves is defined by values around $0.5 \div 2 \mathrm{~m} / \mathrm{s}$.

To lesser extent, works on the detection of stress-related waves were being performed by the Institute of cosmological research and radio wave propagation of FED RAS at Kamchatka Peninsula [8]. In order to solve the task on the research of the properties and efficiency of high-frequency geo-acoustic emission generation in near-surface sedimentary rocks in the conditions of deformation processes activation, the aggregate of observations which consisted of geo-acoustic signals recording system, laser deformograph (one measuring arm), means of meteorological parameters control, data acquisition system were used.

For the purpose of the research of disturbed trend of geo-acoustic emission in on the threshold of strong seismic events at the distances of not more than $200 \mathrm{~km}$ over the period of 6-12 hours, laser measurements of the Earth surface deformation alongside with geoacoustic observations during seismic process activation were performed. As a result, laser deformograph recorded disturbed, from the viewpoint of daily steady diurnal march, deformation process trend - violent oscillations which had high amplitude about $1 \mu \mathrm{m}$. The appearance occurred one day prior to strong seismic event which lasted 8 hours. The evaluation of deformation disturbance velocity amounts to $0.1 \mathrm{~m} / \mathrm{s}$ which corresponds to the velocity of slow stress-related waves.

\section{Methods and technical means of research}

The problem of industrial disasters risk mitigation in large-scale mining is a burning one for Far Eastern region of Russia where deposits, hazardous by rock-bursts, are mined. Among the enterprises exploiting burst-hazardous deposits is "Priargunsky Industrial Mining and Chemical Union", OJSC. Here, uranium deposits of "Streltsovskoe" ore field (south-east Transbaikal) are developed with underground method [9]. At present, rock massif of ore field is to wide extent disturbed by mining operations. The deposit development is 
performed by four underground mines where mining operations have reached the depth of $500-900 \mathrm{~m}$. At them, the entire spectrum of dynamic occurrences of overburden stress, up to strong and destructive rock-burts [9].

In order to conduct comprehensive research for the study of geo-dynamic and seismic environment at the deposits of "Priargunsky Industrial Mining and Chemical Union ", OJSC by the efforts of a row of academic institutes, multilevel system of comprehensive geo-dynamic monitoring, which merged seismic, geo-acoustic and deformational methods and measuring systems into single measuring network, was created and is being improving $[10,11]$.

This system includes multi-channel geo-acoustic automated overburden stress control system - "Prognoz ADS", which allows recording and determining the parameters of acoustic-emission events within the frequency band of $0.5-12 \mathrm{kHz}$ [12]. Microseismic system "Prognoz S" which records seismo-acoustic events with the energy of up to $10^{7} \mathrm{~J}$ within the frequency width $10-1000 \mathrm{~Hz}$ [13].

In order to control deformation field in a mine field and adjacent rock masses, laser deformograph in used geo-mechanical monitoring system [14].

$a$

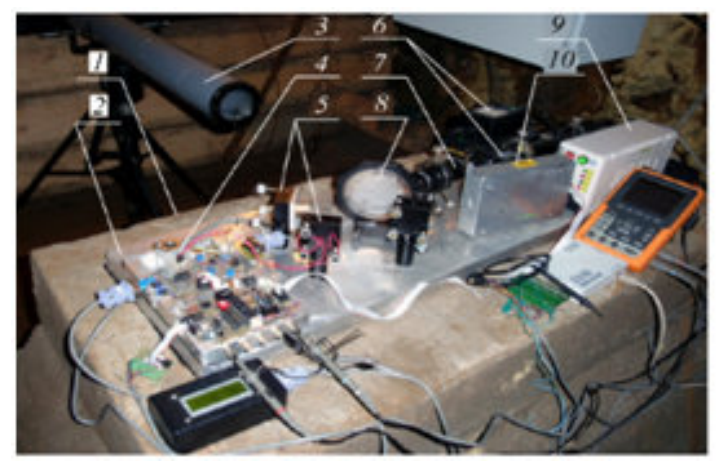

$b$

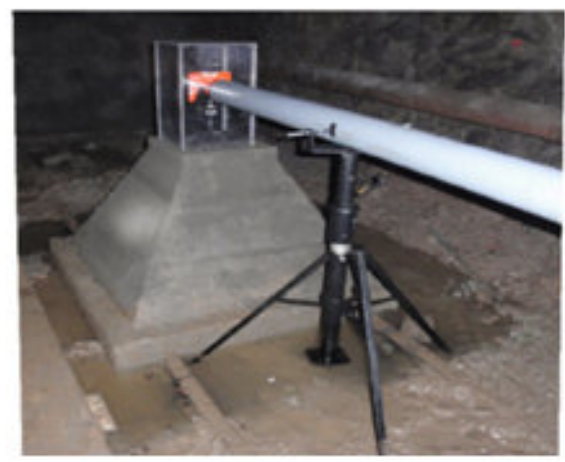

Fig. 1. Laser deformograph installed at geo-dynamic testing area in the vicinity of "Streltsovskoe" ore field: $a$ - interferential unit; $b$ - angle reflector and a fragment of air-filled beam mode guide: 1 concrete bed; 2 - optical bench; 3 - beam mode guide; 4 - monitoring system; 5 - piezoceramic units; 6 - laser with a power unit; 7 - collimator; 8 - separating plate; $9-$ monitoring system power unit; 10 - resonance amplifier.

Laser deformograph is located inside an underground mine opening at the depth of more than $300 \mathrm{~m}$. Optical part of deformograph is assembled based upon modified asymmetrical Michelson interferometer with $50 \mathrm{~m}$ long arm which is targeted at, north-east at the angle of $30^{\circ}$, and frequency-stabilized laser by MellesGriott company. Interferometer is capable of recordng crustal movements with the accuracy of up to $0.1 \mathrm{~nm}$ within the frequency width of $0-1000 \mathrm{~Hz}$ [10-12].

Deformograph optical components are mounted on two concrete blocks rigidly connected with rock mass. Electrooptical part of interferometer, consisting of frequencystabilized laser, optimal control system (monitoring and resonance amplifier systems) and other structural and optical elements of laser deformograph (fig. 1a), is installed on one of them, on another one - angle reflector. Laser ray was spreading between two concrete blocks on air-filled beam mode guide consisting of coupled pipes with inner diameter of 0.1 m (fig. 1b).

In order to ensure required conditions by humidity and temperature, the mine opening is separated, using a separator, into two sections: instrumental section and beam mode guide sections. Air dryer Ballu BDH-25L, set in instrumental section, provides air humidity at the level of $50-60 \%$. Temperature mode of instrumental and beam mode guide sections is 
quite stable with temperature variations of $\pm 2^{\circ} \mathrm{C}$ which allows confident working with interference pattern.

\section{Experimental research findings analysis}

During testing and commissioning, in the course of laser deformograph implementation in measuring cycle, significant spectrum of earth self oscillations from major spheroidal tone ${ }_{0} S_{2}$ to another major spheroidal tone ${ }_{0} S_{0}$ were distinguished by the results of data processing.

Diurnal and semi-diurnal oscillations, the value of which is 23 hours 18 minutes and 11 hours 53 minutes accordingly, were recorded on 14-days deformograph record. Steady registration of diurnal and semi-diurnal oscillations witnesses of the possibility of recording long-period rock massif shift.

It is established that deformograph steadily records rock mass oscillations caused by blasting operations at mines. In order to evaluate the parameters of explosion loads on deformation field in the area of laser deformograph, a range of trial blasts by means of which the directivity graph and its impact on sensitivity of laser deformograph and the degree of signal attenuation in rock massif, was performed.

It is established that various amplitude oscillations, with the interval of about 2 minutes and 3 minutes, are present almost on all sections of deformations records which maybe conditioned by self-frequencies of geo-blocks in the area of deformograph setting. External effects lead to tectonic block oscillations (deformograph recorded their reciprocating movement with the frequency of 2 and 3 minutes).

In order to evaluate earthquake impact on rock massif conditions in the area of mining operations at uranium deposit of "Streltsovskoe" ore field, the development of earthquake and earthquakes forerunners recording procedure, experimental studies with the use of laser deformograph, laser nano-barograph and multi-channel geo-acoustic automated overburden stress control system - "Prognoz ADS" which allows recording and determining the parameters of acoustic-emission events within the frequency width of $0.5-12 \mathrm{kHz}$, were undertaken.

As a case study, the recording results of geo-acoustic system, laser deformograph and laser nano-barograph for the earthquake in Japan on November 16, 2016 with the magnitude of $\mathrm{M}=4.7$ at the distance of $2524 \mathrm{~km}$ away from observation area.

The findings of the analysis of remote earthquakes impact on geo-dynamic activity of "Streltsovskoe" ore field obtained with the use of multi-channel geo-acoustic automated overburden stress control system "Prognoz ADS" are represented on Fig. 2 and 3.

An earthquake duration is depicted as vertical line on fig. 2. It is evident from the figure that the number of events after an earthquake grew twice, and average events energy nearly thrice.

At that, substantial increase of events number was recorded in the block of mining in which they were observed prior to an earthquake (fig. $3 a, b$ ).

It should be noted that such situation was observable not always. In other cases, after an earthquake, an increased geo-dynamic activity was observed in neighbouring blocks, i.e. It was spreading across an mine opening. As authors think it, to significant extent, depends on the direction of seismic wave arrival.

Time record of an earthquake moment with laser deformograph and lase nanobarograph is represented on fig. $4 a, b$.

It is evident from the figures that there is a significant distinction of shapes of deformograph and nano-barograph signals in the moment of earthquake. At the same time, it is clearly evident that the stress in the mine opening varies by the action of seismic wave. 


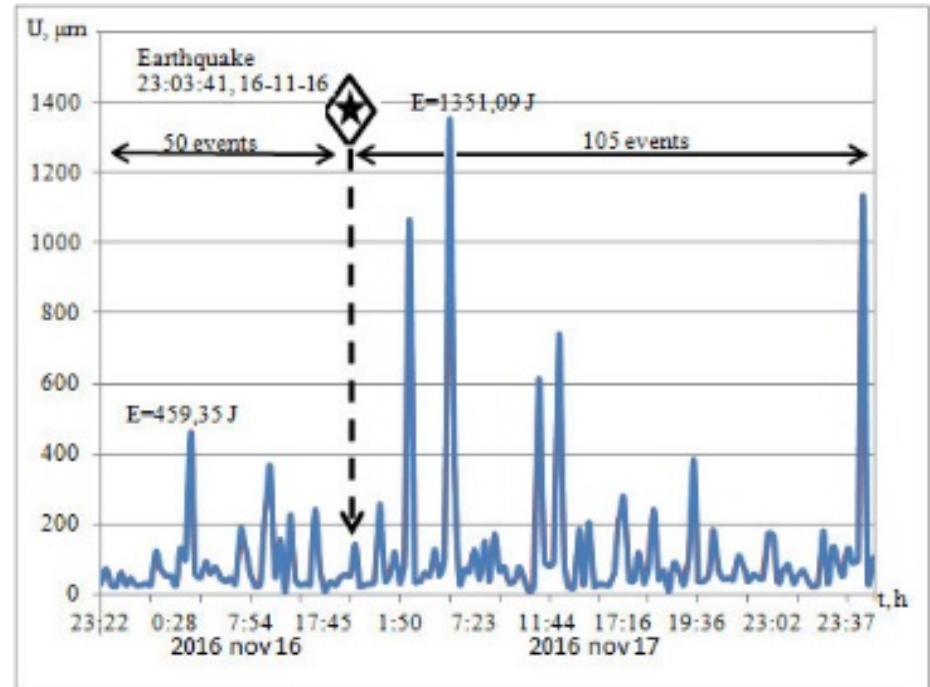

Fig. 2. Diagram of geo-acoustic activity before and after an earthquake

$a$

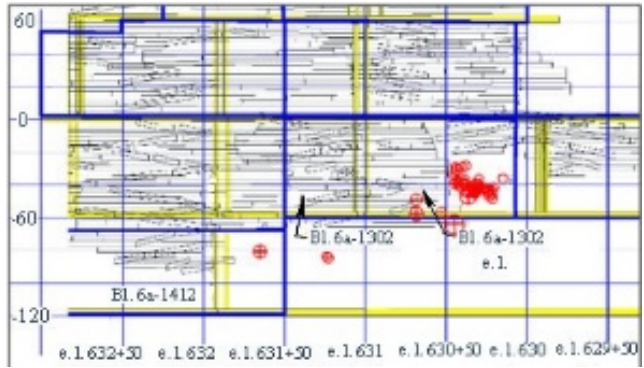

$b$

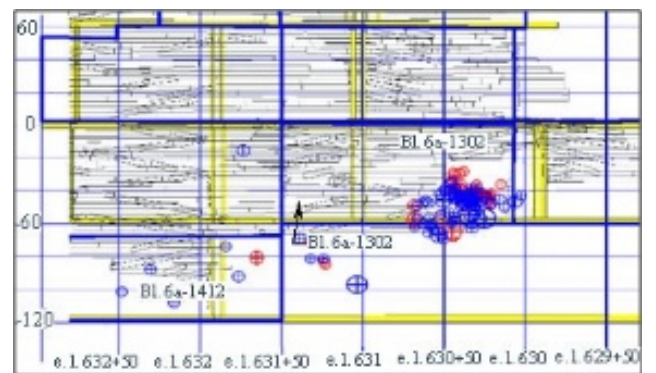

Fig. 3. Geo-acoustic activity, $a$ ) before an earthquake; $b$ ) after an earthquake

In order to establish pre- and post-history of seismic events, double diurnal records, diurnal records before earthquakes and after it were studied. Double diurnal records of deformograph $(a)$ and nano-barograph $(b)$ are represented on fig. 5. Here, unlike the records of an earthquake moment, conspicuous is the fact of high degree of the correlation of results obtained with deformograph and nano-barograph (the difference in the signal polarity is explained by the fact that operating points of Interferometer of nano-barograph and deformograph are selected on various slopes).

$a$

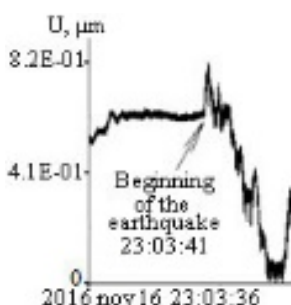

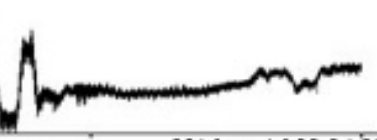

2016 nor $1623: 04: 0020$

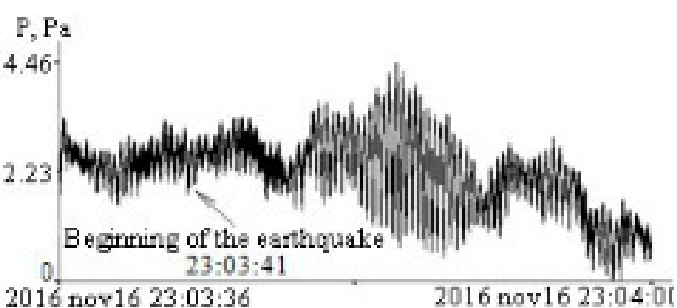

2016 nov16 23:04:01

Fig. 4. Signals recorded by deformograph $(a)$ and nano-barograph $(b)$ 
$a$

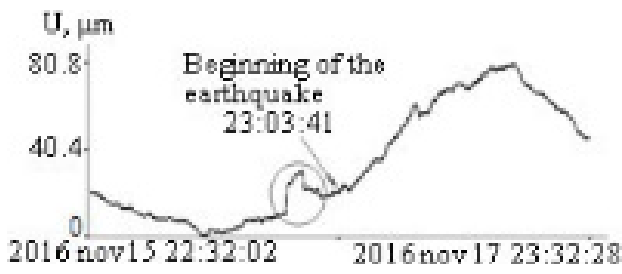

$b$

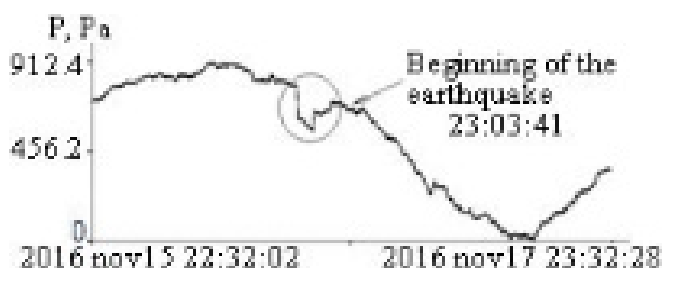

Fig. 5. Record of deformation signals recorded by deformograph $(a)$ and nano-barograph $(b)$

The high degree of correlation is connected, apparently, with the fact that deformograph includes air-filled beam mode guide and refraction index variations overlap mechanical oscillations. Same situation is observed in all durable (semi-diurnal, diurnal) records. At that, mechanical oscillations become noise contaminated with variations of refraction index which depends on the stress. The exclusion of refraction index variations impact on deformation measurements is possible to achieve by several ways. First, beam mode guide should be no air-filled, but evacuated to pressures of around $10^{-3} \mathrm{~atm}$ and thus minimize the dependence of refraction index on stress and temperature. Second way - installation of one more measuring arm of deformograph orthogonal to the first one which enables obtaining clear differential signal. And the third way is to introduce corrections in postprocessing.

In author's opinion, the most advanced is the second way. In case of its realization, it becomes possible not only to increase deformograph resolution by means of interference compensation, but also the possibility of judging of stress-related wave arrival direction emerges which essentially widens the potential of high-precision laser measurements.

One more peculiarity of the results obtained is the presence in each various earthquakes record bay signals of substantive amplitude (on fig. 5 they are encircled).

This may be the reaction of the massif to industrial blasts. Accompanying oscillations with the frequency of $95 \mathrm{~Hz}$, which are steadily recorded in the analysis of blast records, point at that. If to suggest that a blast excited oscillations of block (possibly stress-related wave, local earthquake, block movement) with sufficient power, the block oscillations may shake adjacent medium. In case of accumulated rocks stress such oscillation may cause their destruction. It is fair to assume that the oscillations reached laser deformograph in the shape of bay excitations. It is apparent from figures that deformation goes back almost in the initial point. Otherwise, it would be well to suggest that it's growing somewhere which leads to the destruction and devolution.

\section{Conclusions}

1. As the researcher' works showed, deformation and wave processes in earth crust are triggering mechanism for various high-energy seismic events (earthquakes, rock bursts, etc.). At the same time, they may be forerunners of these events. Topical becomes the tasks of their detection and recording. The results of research conducted demonstrate that in case availability of required measuring means for recording deformation and wave processes as well as corresponding guidance papers for distinguishing pendulum waves, the opportunity to control dynamic and kinematic attributes of the latter on regional and world-wide basis appears.

2. According to the data of high-precision deformation control at geo-dynamic testing area in the proximity of "Streltsovskoe" ore field it has been established that seismic waves from strong earthquakes have significant impact on deformation field what may be an extract factor initiating dynamic occurrences of overburden stress at "Antei" deposit. 
3. It has been experimentally proven that deformation shaking with oscillatory periods within the width of 0.5-2 hours for 1.5-2 days before seismic events exists. Velocity range of pendulum stress-related waves of around $0.5 \div+2 \mathrm{~m} / \mathrm{s}$ was calculated. It should be assumed that, determining and analysing records with rock-bursts registration in the area of "Streltsovskoe" ore field at rather small distances of seismic events from observation area (several kilometres), an opportunity to record stress-related waves, determination of their arrivals time and amplitude-time characteristics of deformational wave-train may be obtained. This will enable significantly increasing the reliability of energy geo-dynamic events in burst hazardous rock in the development of deposits in aid of prevention of catastrophic events.

\section{References}

1. V.V. Adushkin S.B. Turuntaev, Technogenic seismic activity - induced and triggered. IDG RAS, 2015.

2. I.Yu. Rasskazov, Monitoring and management of rock pressure on mines of Far East region. Mountain book. p. 329. (2008)

3. Henryk M., Mutke G. Z. Journal of Seismology. 17 (4). 1139-1148. (2013)

4. Paige E. Snelling, Laurent Godin, Stephen D. McKinnon. International Journal of Rock Mechanics and Mining Sciences. 58. 166-179. (2013)

5. M.V. Kurlenia V.N. Oparin. Journal of Mining Science. 4. (1990)

6. S.N. Bagaev, V.N. Oparin, V.A. Orlov, S.V. Panov, M.D. Parushkin. Journal of Mining Science. 3. (2010)

7. V.N. Oparin and others, Methods and systems of seismo-deformation monitoring of induced earthquakes and mine bumps. 1, 2. Publishing house of Siberian Branch of Russian Academy of Sciences. (2009)

8. I.A. Larionov, B.M. Shevtsov. The problems of comprehensive geo-physical monitoring of Far East of Russia. IKIR FED RAS: Petropavlovsk-Kamchatsky city. (2009)

9. I.Yu. Rasskazov B.G. Saksin, V.A. Petrov, B.A. Prosekin. Journal of Mining Science. 3. 3-13. (2012)

10. V.A. Petrov, A.B. Leksin, V.A. Sankov, V.V. Pogorelov, I.Yu. Rasskazov, GIS-based 3D geodynamic modelling of Transbaikalia, Russia, Int. Conf. GeoFrankfurt'2014 "Earth System Dynamics". Goethe University Frankfurt a, Main. SDGG Heft 85, Abstract Volume. pp. 471. (2014)

11. I.Yu. Rasskazov, A.V. Gladyr, P.A. Anikin, V.S. Sviatetskii, B.A. Prosekin. Mining Magazine. 8 (2). 9-14. (2013)

12. I.Yu. Rasskazov, V.A. Lugovoi, G.A. Kalinov, A.V. Gladyr, P.A. Anikin, M.I. Rasskazov and D.I. Tsoi. Proceedings of the 8-th International Symposium on Rockbursts and Seismicity in Mines (Russia, Saint-Petersburg - Moscow. September 1-7, 2013). pp. 121-124. (2013)

13. A.V. Gladyr, V.I. Miroshnikov, Iu.I. Bolotin and others. Mining information-analytical bulletin. 5. $174-180$. (2012)

14. I.Yu. Rasskazov, V. A. Lugovoi, B.G. Saksin, D. I. Tsoi, G.I. Dolgikh, S. G. Dolgikh, V. A. Petrov. Journal of Mining Science. 52 (6). 1052-1059. (2016)

15. Takemoto Shuzo, Momose Hideo, Araya Akito, etc. Journal of Geodynamics. 41. 23-29. (2006). 